\title{
OSSEOINTEGRATION OF BIOCHEMICALLY MODIFIED IMPLANTS IN AN OSTEOPOROSIS RODENT MODEL
}

\author{
B. Stadlinger ${ }^{1, *}$, P. Korn², N. Tödtmann², U. Eckelt², U. Range ${ }^{3}$, A. Bürki ${ }^{4}$, S.J. Ferguson ${ }^{5}$, I. Kramer ${ }^{6}$, A. Kautz ${ }^{7}$, \\ M. Schnabelrauch 7 , M. Kneissel ${ }^{6}$ and F. Schlottig ${ }^{8}$
}

\author{
${ }^{1}$ Clinic of Cranio-Maxillofacial and Oral Surgery, University of Zurich, Zurich, Switzerland \\ ${ }^{2}$ Department of Oral and Maxillofacial Surgery, Technische Universität Dresden, Dresden, Germany \\ ${ }^{3}$ Institute for Medical Informatics and Biometry, Technische Universität Dresden, Dresden, Germany \\ ${ }^{4}$ Institute for Surgical Technology and Biomechanics, University of Bern, Switzerland \\ ${ }^{5}$ Institute for Biomechanics, ETH Zurich, Zurich, Switzerland \\ ${ }^{6}$ Musculoskeletal Disease Area, Novartis Institutes for BioMedical Research, Basel, Switzerland \\ ${ }^{7}$ Innovent e.V., Biomaterials Department, 07745 Jena, Germany \\ ${ }^{8}$ Thommen Medical AG, Waldenburg, Switzerland
}

\begin{abstract}
The present study examined the impact of implant surface modifications on osseointegration in an osteoporotic rodent model. Sandblasted, acid-etched titanium implants were either used directly (control) or were further modified by surface conditioning with $\mathrm{NaOH}$ or by coating with one of the following active agents: collagen/chondroitin sulphate, simvastatin, or zoledronic acid. Control and modified implants were inserted into the proximal tibia of aged ovariectomised (OVX) osteoporotic rats ( $n=32$ /group). In addition, aged oestrogen competent animals received either control or $\mathrm{NaOH}$ conditioned implants. Animals were sacrificed 2 and 4 weeks post-implantation. The excised tibiae were utilised for biomechanical and morphometric readouts ( $n=8 /$ group/readout). Biomechanical testing revealed at both time points dramatically reduced osseointegration in the tibia of oestrogen deprived osteoporotic animals compared to intact controls irrespective of $\mathrm{NaOH}$ exposure. Consistently, histomorphometric and microCT analyses demonstrated diminished bone-implant contact (BIC), periimplant bone area (BA), bone volume/tissue volume (BV/ TV) and bone-mineral density (BMD) in OVX animals. Surface coating with collagen/chondroitin sulphate had no detectable impact on osseointegration. Interestingly, statin coating resulted in a transient increase in BIC 2 weeks post-implantation; which, however, did not correspond to improvement of biomechanical readouts. Local exposure to zoledronic acid increased BIC, BA, BV/TV and BMD at 4 weeks. Yet this translated only into a non-significant improvement of biomechanical properties. In conclusion, this study presents a rodent model mimicking severely osteoporotic bone. Contrary to the other bioactive agents, locally released zoledronic acid had a positive impact on osseointegration albeit to a lesser extent than reported in less challenging models.
\end{abstract}

Keywords: Implant; osseointegration; osteoporosis; animal model; surface coating; histomorphometry; biomechanics.

*Address for correspondence:

Bernd Stadlinger

Clinic of Cranio-Maxillofacial and Oral Surgery

University of Zurich

Plattenstr. 11

CH-8032 Zurich, Switzerland
Telephone Number.:+41 446343290

FAX Number.:+41 446344328

E-mail: bernd.stadlinger@zzm.uzh.ch

\section{Introduction}

Subsequent to placement of an implant into bone, the osseous wound undergoes sequentially haemostasis, inflammation and proliferation analogous to the phases of fracture healing (Schindeler et al., 2008). Primary implant stability is enabled by an interlock between an implant and the host bone. During osseous healing, host bone in proximity to the implant will be resorbed and new woven bone will be formed (Davies, 1998). This leads to a transient decrease in stability until secondary implant stability is established. Remodelling processes around the implant will continue for an extended time period depending on species, loading of the implant, and bony template (Branemark et al., 1977).

The implant surface structure and composition has an impact on the attachment of proteins and subsequent cellular processes, which are relevant to implant osseointegration (Junker et al., 2009). Ideally, an implant should be characterised by high primary stability and a sufficient and persistent degree of osseointegration (Esposito et al., 1998; Sennerby and Meredith, 2008; Martin et al., 2009). In recent years, several techniques of surface modification emerged in order to stimulate peri-implant bone formation and thus osseointegration. It was demonstrated, that roughened surfaces positively influence biomechanical anchorage and bone formation (Butz et al., 2006). Moreover, surface conditioned implants showed increased rates of bone formation (Buser et al., 2004; Stadlinger et al., 2009b). Another approach, which is increasingly explored, is the coating of implant surfaces with components of the bone extracellular matrix in order to influence mediators involved in early phases of osseointegration (Rammelt et al., 2007; Stadlinger et al., 2009a). Such surface coatings have been shown to increase bone formation in comparison to sandblasted, acid-etched implants in uncompromised host bone (Stadlinger et al., 2009a). From the clinical point of view, stimulation of osseointegration is of particular interest in compromised bone. Osteoporosis, characterised by low bone mass and increased bone fragility, is a skeletal 
disorder that represents such a compromised setting. The correlation between systemic bone and oral bone loss has been demonstrated (Jeffcoat, 2005; Wactawski-Wende et al., 2005), a correlation to implant loss, however, has not been found (Holahan et al., 2008). A common therapy for osteoporotic patients is the application of drugs that inhibit bone resorption and thus further bone loss. Bisphosphonates represent the largest group of these anti-resorptive drugs currently in clinical use (Rachner et al., 2011). Accordingly, coating of implant surfaces with bisphosphonates has been explored for its ability to improve implant osseointegration and testing in animal studies yielded positive results (Wermelin et al., 2007; Wermelin et al., 2008a). Another approach is to improve osseointegration by stimulation of bone formation. This has been explored utilising statin coated implants (Moriyama et al., 2010), based on the finding that statins induce bone morphogenetic protein-2 (BMP-2) expression and promote osteoblastic BMP signalling (Mundy et al., 1999), which is critical during osseointegration and fracture healing. Also for this approach positive findings were reported in a pre-clinical animal model (Du et al., 2009).

In the present study we analysed biochemically modified implants in a severely compromised setting. Implants were inserted into the proximal tibia of oestrogen deprived rats with established osteoporosis. The aim of the study was to test whether these biochemical modifications that have been reported previously to enhance osseointegration in healthy bone would yield a similar effect in osteoporotic bone.

\section{Materials and Methods}

\section{Animals}

The experimental protocol of this study and animal care conformed to the Swiss federal law for animal protection under the control of the Basel-Stadt Cantonal Veterinary Office, Switzerland. Hundred and sixty, six-month old female virgin Wistar rats underwent bilateral ovariectomy (OVX), while another 64 rats underwent sham surgery and remained intact. Fourteen weeks post-surgery the animals were divided into five OVX- and two non-OVX groups (32 rats/group) with an even distribution of proximal tibial bone-mineral density as assessed by microCT and body weight within the OVX groups and the intact groups. Each of the seven groups was randomly divided into two subgroups (16 rats/sub-group), designated to 2 and 4 weeks of implant healing. The animals received one implant in the left proximal tibia metaphysis. Tibial bone samples from eight animals per sub-group were assessed by microCT and histomorphometry; the additional eight samples were utilised for biomechanical testing.

\section{Implants}

Experimental threaded titanium implants (grade 4) with an inner diameter of $1.1 \mathrm{~mm}$, outer diameter of $1.7 \mathrm{~mm}$ and a length of $3.0 \mathrm{~mm}$ (Thommen Medical AG, Waldenburg, Switzerland) received different surface treatments. Implants had a cuboid implant head in order to allow biomechanical testing. The surface of all implants had been sandblasted and thermally acid-etched (SAE). The $\mathrm{S}_{\mathrm{a}}$ value of this procedure is approximately $2.0 \mu \mathrm{m}$ (Stadlinger et al., 2012). Sixty-four implants were conditioned by a solution containing hydroxide ions prior to implant placement as described previously (Stadlinger et al., 2012). Thirty-two implants were coated in a solution of $1 \mathrm{mg} / \mathrm{mL}$ collagen type I and chondroitin sulphate at a concentration of $50 \mu \mathrm{g} /$ $\mathrm{mL}$, as described previously (Stadlinger et al., 2009a). Another 32 implants were coated with a simvastatinchitosan complex using a modified spin coating procedure. A homogeneous suspension of $57 \mu \mathrm{g}$ simvastatin complex in $5 \mu \mathrm{L}$ acetone containing $35 \mu \mathrm{g}$ simvastatin per implant has been used. The implants were fixed in a horizontally positioned stirring motor (Eurostar Digital, IKA-Werke, Staufen, Germany) rotating at a constant speed of $300 \mathrm{rpm}$. The simvastatin suspension was dropped into the implant thread turns using a precision pipette (Eppendorf Reseach, Hamburg, Germany; 0.5-10 $\mu$ L volume), which was positioned at a distance of 1-2 mm over the rotating implant. Implant rotation results in a homogeneous distribution of the coating within the implant thread.

Finally, 32 implants were coated with a zoledronic acid-stearate complex using the method described above. A homogeneous suspension of $23.8 \mu \mathrm{g}$ of zoledronic-acidstearate complex in acetone containing $8.5 \mu \mathrm{g}$ zoledronic acid per implant was used. After coating, both simvastatin and zoledronate-containing implants were stored for $30 \mathrm{~min}$ at $60^{\circ} \mathrm{C}$ to remove the solvent. All implants were sterilised by gamma-radiation.

In vitro release studies have been performed measuring the amount of released simvastatin and zoledronic acid, respectively, within a time period of 14 days. For this purpose titanium discs (grade 4, $15 \mathrm{~mm}$ in diameter, surface treated in the same way as the implants) coated with the simvastatin-chitosan and the zoledronic acidstearate complex, respectively, were stored into simulated body fluid (SBF) medium (simvastatin-coated discs) and, physiological $\mathrm{NaCl}$ solution (zoledronic acid-coated discs) respectively, and the released amount of bioactive agent after 1, 2, 3, 5, 7 and 14 days was measured. The amount of released simvastatin and zoledronic acid was quantified by UV/Vis spectroscopy. For zoledronic acid quantification the spectrophotometric method reported by Gallez et al. (1988) was employed. All experiments were run in duplicates. Release data are shown in Table 1.

\section{Implant procedure}

Animals were anaesthetised with ketamine and xylazine by intraperitoneal injection and received buprenorphine for analgesic purposes. All operative procedures were performed under sterile conditions. For implant placement, a $15 \mathrm{~mm}$ longitudinal incision was made along the medial side of the tibia and a musculoperiosteal flap was elevated. A conical drill with a diameter of 1.1-1.5 mm in diameter was used to generate, under water cooling, an osteotomy $2 \mathrm{~mm}$ distal to the growth plate of the proximal left tibia. Implants were placed using an implant screwdriver. After placement, a rounded polyether ether ketone healing-cap was placed on the cuboid implant top. The soft tissue was repositioned and sutured in two layers, using resorbable sutures (Safil 6x0, Braun, Melsungen, 
Table 1. In vitro release of simvastatine and zoledronic acid.

\begin{tabular}{|c|c|c|c|c|c|c|}
\hline \multirow[b]{3}{*}{ Complex } & \multicolumn{6}{|c|}{ Cumulative amount of released agent [\%] } \\
\hline & \multicolumn{6}{|c|}{ Release time [d] } \\
\hline & 1 & 2 & 3 & 5 & 7 & 14 \\
\hline $\begin{array}{l}\text { Simvastatin- } \\
\text { chitosan }\end{array}$ & $20.4 \pm 2.8$ & $22.3 \pm 3.1$ & $22.7 \pm 3.1$ & $22.9 \pm 3.1$ & $23.1 \pm 3.1$ & $23.2 \pm 3.1$ \\
\hline $\begin{array}{l}\text { Zoledronic acid- } \\
\text { stearate }\end{array}$ & $34.2 \pm 2.8$ & $49.5 \pm 5.5$ & $62.9 \pm 6.1$ & $69.5 \pm 6.2$ & $71.1 \pm 4.7$ & $71.1 \pm 4.7$ \\
\hline
\end{tabular}

Table 2. Results of microcomputed tomography at two and four weeks $(\mu \mathrm{CT})$.

\begin{tabular}{|c|c|c|c|c|c|c|c|c|c|c|c|}
\hline \multirow[b]{2}{*}{ Group } & \multirow[b]{2}{*}{ Surface } & \multicolumn{2}{|c|}{ Healing time } & \multicolumn{3}{|c|}{ BIC cancellous bone } & \multicolumn{3}{|c|}{ BV/TV $200 \mu \mathrm{m}$} & \multicolumn{2}{|c|}{ BMD $200 \mu \mathrm{m}$} \\
\hline & & [weeks] & $n$ & {$[\%]$} & SD & $n$ & {$[\%]$} & SD & $n$ & [mgHA/ccm] & SD \\
\hline \multirow{4}{*}{$\begin{array}{l}\text { non- } \\
\text { OVX }\end{array}$} & reference & 2 & 7 & $68.6 \#$ & 10.8 & 7 & $48.6 \#$ & 13.3 & 7 & 883.9\# & 107.5 \\
\hline & reference & 4 & 7 & $67.7 \#$ & 13.9 & 7 & $50.5 \#$ & 17.1 & 7 & $891.3 \#$ & 152.3 \\
\hline & conditioned & 2 & 6 & $69.5 \#$ & 14.9 & 7 & $50.7 \#$ & 15.7 & 7 & 891.0\# & 140.5 \\
\hline & conditioned & 4 & 6 & $62.1 \#$ & 13.7 & 7 & $46.6 \#$ & 17.9 & 7 & 861.4\# & 161.7 \\
\hline \multirow{10}{*}{ OVX } & reference & 2 & 6 & $31.3^{*}$ & 11.9 & 7 & $10.8^{*}$ & 5.7 & 7 & $491.2 *$ & 105.8 \\
\hline & reference & 4 & 6 & $20.6^{*}$ & 2.4 & 7 & $4.7 *$ & 3.5 & 7 & $361.6^{*}$ & 62.6 \\
\hline & conditioned & 2 & 6 & $30.2 *$ & 10.7 & 7 & $11.8^{*}$ & 5.1 & 8 & $470.7 *$ & 89.6 \\
\hline & conditioned & 4 & 7 & $25.4^{*}$ & 4.5 & 7 & $6.4^{*}$ & 2.4 & 7 & $404.5^{*}$ & 38.6 \\
\hline & collagen/CS & 2 & 8 & $36.3 *$ & 6.7 & 8 & $12.6^{*}$ & 4.3 & 8 & $503.9 *$ & 72.8 \\
\hline & collagen/CS & 4 & 7 & $21.4^{*}$ & 3.8 & 7 & $3.8 *$ & 1.7 & 7 & $355.8 *$ & 24.8 \\
\hline & simvastatin & 2 & 6 & $50.8 \#$ & 6.6 & 7 & $19.3^{*}$ & 6.4 & 7 & $592.7 *$ & 81.5 \\
\hline & simavstatin & 4 & 6 & $35.6^{*}$ & 10.7 & 7 & $10.5^{*}$ & 5.4 & 7 & $453.9 *$ & 83.9 \\
\hline & $\begin{array}{l}\text { zoledronic } \\
\text { acid }\end{array}$ & 2 & 6 & $31.8^{*}$ & 8.4 & 7 & $15.1^{*}$ & 8.8 & 7 & $532.5^{*}$ & 125.7 \\
\hline & $\begin{array}{l}\text { zoledronic } \\
\text { acid }\end{array}$ & 4 & 8 & $47.8 * \#$ & 10.4 & 8 & $23.0 * \#$ & 11.3 & 8 & $602.1 * \#$ & 128.0 \\
\hline
\end{tabular}

Significantly different $(p \leq 0.05)$ compared to reference in non- OVX $(*)$ or OVX $(\#)$ rats at the same time point.

Germany). An aerosol bandage was applied (Flint MED, Togal-Werk AG, München, Germany) and wound healing was controlled daily for the first week and twice per week during the following healing periods. All animals received fluorochrome markers by subcutaneous injection 10 days (alizarin complexone, $20 \mathrm{mg} / \mathrm{kg}$; Merck, Zug, Switzerland) and 3 days (calcein, $30 \mathrm{mg} / \mathrm{kg}$, Sigma-Aldrich, Steinheim, Germany) prior to sacrifice.

\section{Tissue processing}

After sacrifice, the left tibiae were harvested. The proximal halves were fixed in Schaffer's solution for $24 \mathrm{~h}$ at $4{ }^{\circ} \mathrm{C}$, followed by $70 \%$ ethanol. Following ex vivo microCT analysis, the samples were dehydrated and embedded in methylmethacrylate to generate $50 \mu \mathrm{m}$ ground sections cut in parallel to the implant length axis and perpendicular to the tibial axis as described previously (Donath and Breuner, 1982). Fluorescent microscopy was performed prior to Masson-Goldner staining.

\section{Computed tomography}

For even distribution of animals into groups prior to implant surgery, cross-sectional apparent cancellous bone-mineral density (BMD) was evaluated in the left proximal tibia metaphysis by peripheral quantitative computed tomography (pQCT, Norland XCT-2000 Stratec, Pforzheim, Germany, fitted with an Oxford 50 AM X-ray tube and a collimator of $1 \mathrm{~mm}$ diameter; voxel size: $0.2 \mathrm{x}$ 0.2 x $1 \mathrm{~mm}$; scan speed: scout view $20 \mathrm{~mm} / \mathrm{s}$; final scan $10 \mathrm{~mm} / \mathrm{s}, 1$ block, contour mode 1, peel mode 2; threshold: $610 \mathrm{mg} / \mathrm{cm}^{3}$ ).

Ex vivo $\mathrm{CT}$ measurements were performed with a microCT40 (Scanco Medical, Brüttisellen, Switzerland; voxel size, $10 \mu \mathrm{m}$; high resolution; 192 slices, energy, $70 \mathrm{E}(\mathrm{kVp}), 114 \mu \mathrm{A}$, high resolution, integration time $300 \mathrm{~ms}$, conebeam continuous rotation) as previously described (Rebaudi et al., 2004). Briefly, bone and titanium implant were distinguished using the appropriate Gaussian filters (sigma 1.2 bone, 2.0 titanium; support 2 bone, 

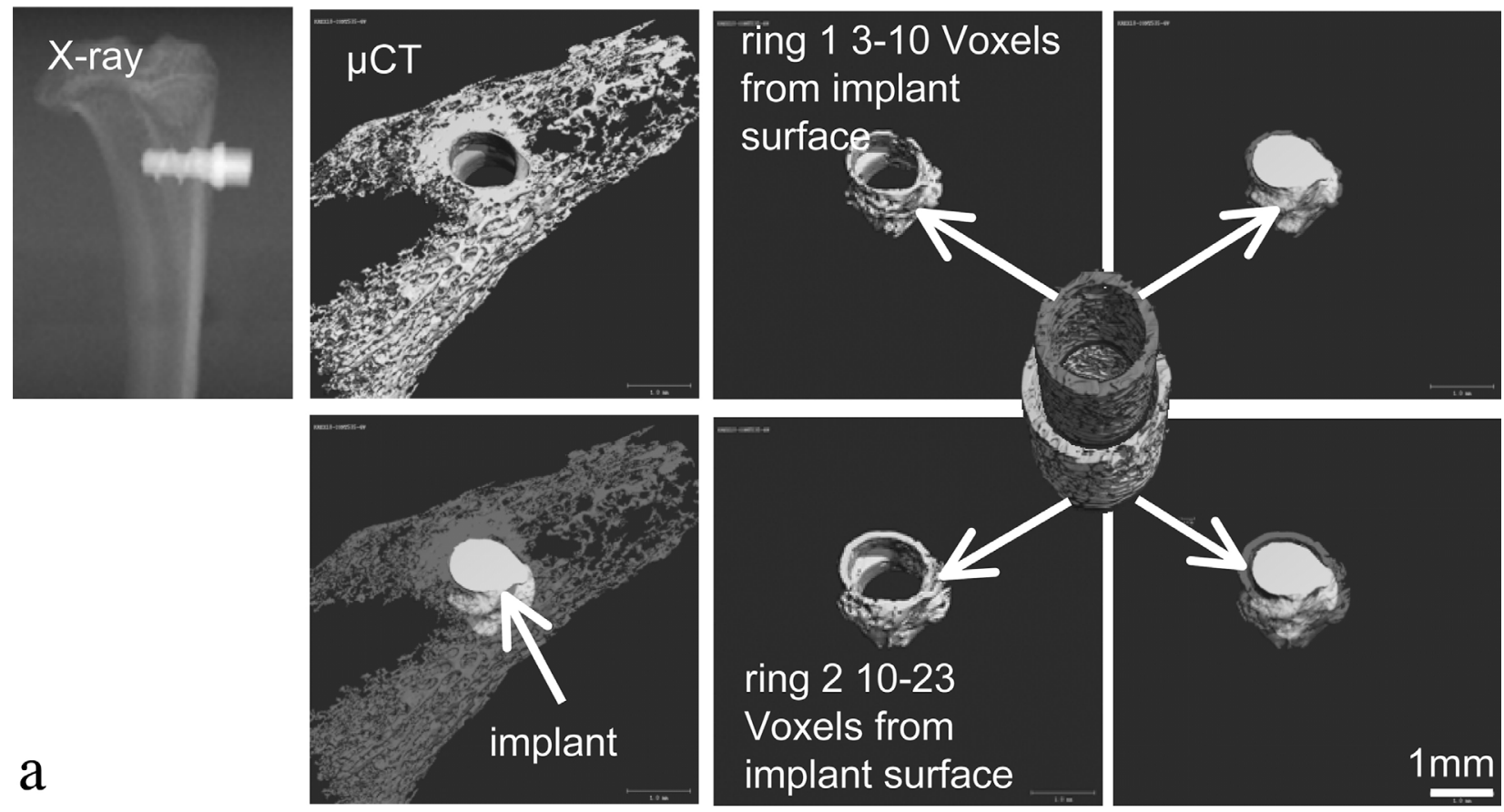

a
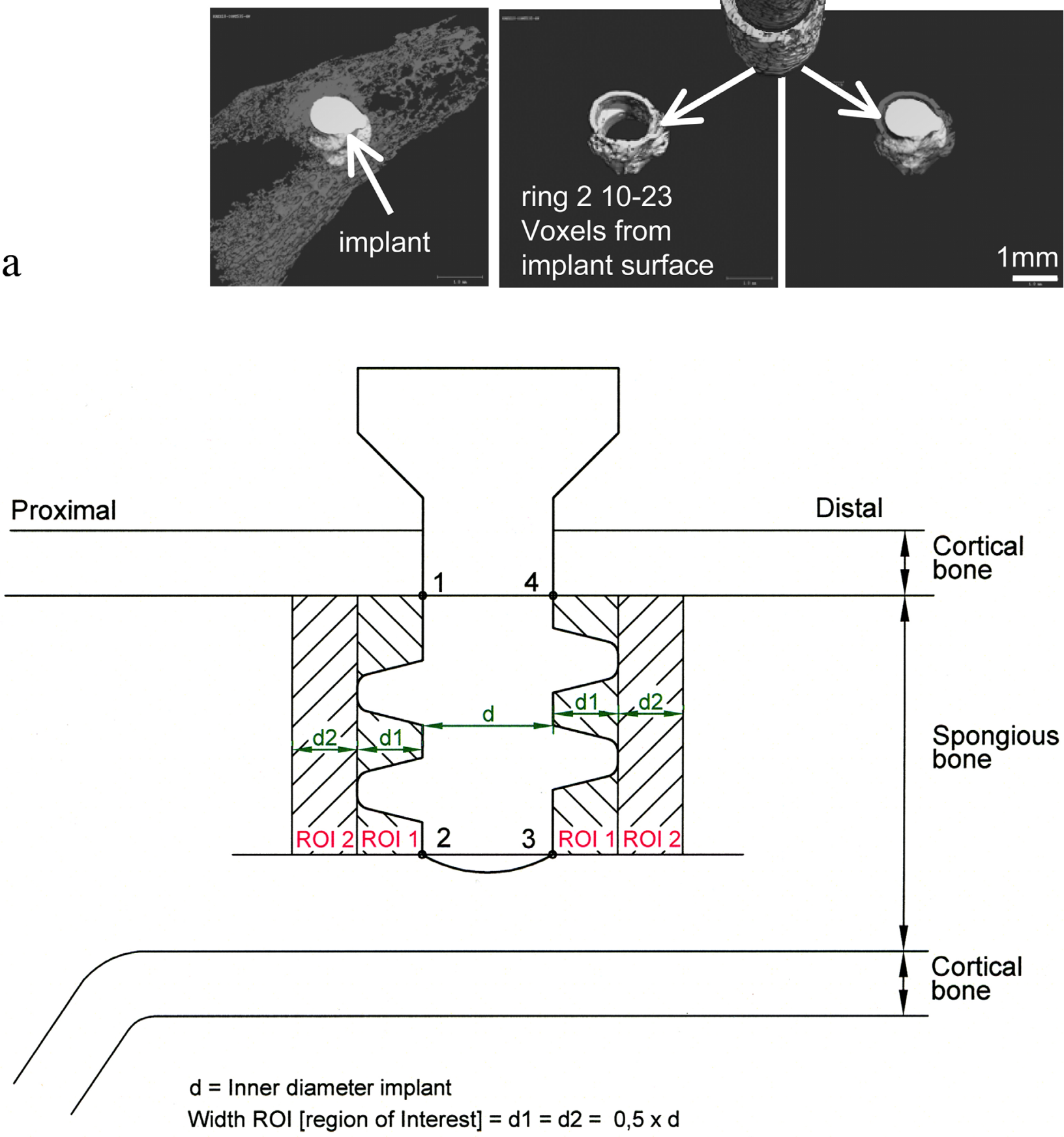

Measured areas : $\overline{\mathrm{P}_{1} \mathrm{P}_{2}}+\overline{\mathrm{P}_{3} \mathrm{P}_{4}}=$ Bone- implant contact

b

$$
\begin{array}{ll}
\text { ROI } 1 & =\text { Adjacent bone area } \\
\text { ROI } 2 & =\text { Distant bone area }
\end{array}
$$

Fig, 1. Regions of interest for (a) micro-CT measurements and (b) histomorphometric measurements. 

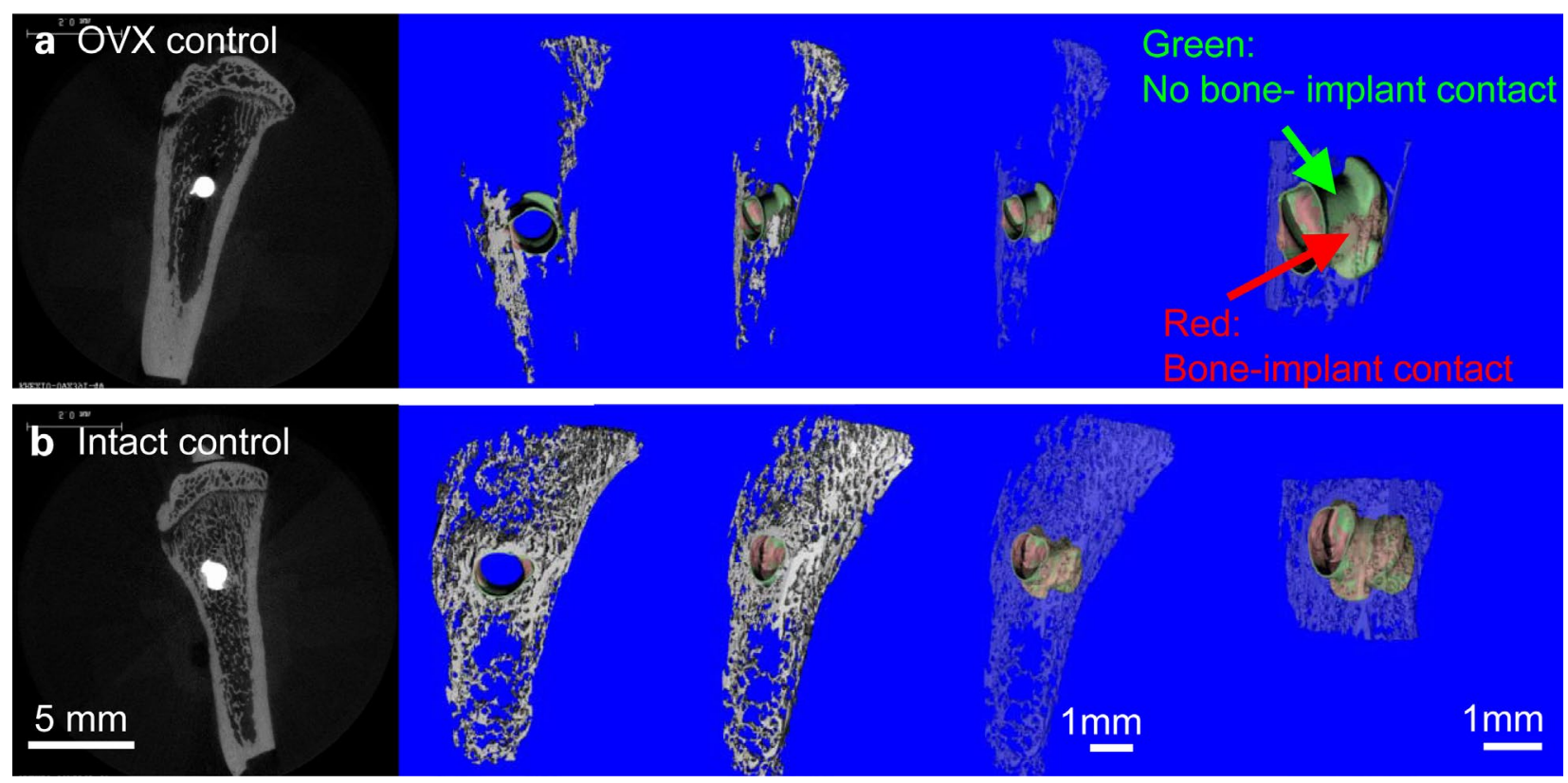

Fig. 2. MicroCT images exemplifying the difference in bone template in the proximal tibia between oestrogen competent (a) and oestrogen deprived (b) animals four weeks post-implantation.

3 titanium) and threshold procedures (bone: 370-700; titanium implant 700-1000). BMD and bone volume/tissue volume (BV/TV) were determined in the cancellous bone region surrounding the implant (3 to 10 voxels distance from the implant) and in a neighbouring region in further distance to the implant surface (10 to 23 voxels distance from the implant) (Fig. 1a). Since results did not differ between the two regions, data were merged for the results presented in Table 2 and reflect a total width of $200 \mu \mathrm{m}$. In addition, bone-implant contact (BIC) was determined. In order to avoid artefacts due to the titanium implant, BIC measurements were performed at a distance of $30 \mu \mathrm{m}$ (i.e., 3 voxels) from the surface. The number of surface voxels attached to bone at this distance divided by the total number of implant surface voxels was used to derive the BIC in percentage, as described by Rebaudi et al. (2004).

\section{Histomorphometry}

Fluorescence microscopy was performed at up to $40 \mathrm{x}$ magnification (Olympus BX 61, Hamburg, Germany). Polyfluorochrome labels were qualitatively analysed for bone growth dynamics, location and label sequence. Subsequently stained sections were imaged using a motorised measuring stage (Märzhäuser, Wetzlar, Germany) for multiple alignment scanning connected to a computerised system of histomorphometry (Cell^ $\mathrm{F}$, Imaging Software for Life Science, Olympus). BIC was measured in the cancellous bone compartment along the implant surface. The apex of the implant was not included. Cancellous bone area per tissue area (BA/TA) was measured in a region adjacent to the implant and in a surrounding distant area (Fig. 1b).

\section{Biomechanical evaluation}

All specimens underwent biomechanical testing at the day of harvest. Healing caps were removed and the tibiae were embedded in dental plaster (Fujirock EP, Improved type 4 dental stone, GC Europe, Kortrijk, Belgium), using a custom potting device which provides coaxial alignment of the implant and the testing machine. Specimens were mounted on a servohydraulic testing machine (MTS 858 Mini Bionix, MTS Systems, Eden Prairie, MN, USA) and connected to a $2 \mathrm{Nm}$ load cell/signal amplifier (D2209, Lorenz Messtechnik, Alfdorf, Germany, accuracy $2 \mathrm{Nmm}$ ). A mechanical flex clutch was used to ensure neutral initial fixation (no moment). Implants were rotated counterclockwise $(\mathrm{CCW})$ at a constant rate of $0.5 \%$ s. Moment and angle data were recorded for subsequent analysis with a custom script in MATLAB (R2008, The MathWorks, Natick, MA, USA) to determine the removal torque (RT: $\mathrm{Nmm})$ and interfacial stiffness $\left(\mathrm{Nmm} /{ }^{\circ}\right)$ values.

\section{Statistical analysis}

The data are presented as mean values plus/minus standard deviation. Data distribution was tested by the KolmogorovSmirnov-Test. Variance analysis of all groups by analysis of variance (ANOVA) and following Bonferoni adjusted multiple comparisons of mean values were performed. Differences in variance between measurement parameters were analysed by Pearson correlation coefficient. The level of significance was set at $\alpha=0.05$ in all statistical tests. Statistical analysis was performed by SPSS for Windows ${ }^{\circledR}$ 19 (SPSS, Chicago, IL, USA).

\section{Results}

\section{Animals}

Six animals died during anaesthesia and one animal was euthanised due to wound healing complications. Seven histological samples were not included in the histological analysis due to bicortical insertion. 
Table 3. Results of histomorphometry at two and four weeks.

\begin{tabular}{|c|c|c|c|c|c|c|c|c|c|}
\hline \multirow[b]{2}{*}{ Group } & \multirow[b]{2}{*}{ Surface } & \multicolumn{2}{|c|}{ Healing time } & \multicolumn{2}{|c|}{ BIC cancellous bone } & \multicolumn{2}{|c|}{ BA adjacent } & \multicolumn{2}{|c|}{ BA distant } \\
\hline & & [weeks] & $n$ & {$[\%]$} & SD & {$[\%]$} & SD & {$[\%]$} & SD \\
\hline \multirow{4}{*}{$\begin{array}{l}\text { non- } \\
\text { OVX }\end{array}$} & reference & 2 & 7 & $52.9 \#$ & 14.6 & $47.1 \#$ & 19.9 & $28.0 \#$ & 13.6 \\
\hline & reference & 4 & 6 & $66.5 \#$ & 11.5 & $42.6 \#$ & 11.8 & $29.3 \#$ & 11.2 \\
\hline & conditioned & 2 & 7 & $55.3 \#$ & 13.6 & $43.1 \#$ & 12.7 & $28.3 \#$ & 9.7 \\
\hline & conditioned & 4 & 7 & $51.1 \#$ & 12.0 & $43.0 \#$ & 13.5 & $30.6 \#$ & 10.0 \\
\hline \multirow{10}{*}{ OVX } & reference & 2 & 8 & $24.1 *$ & 8.6 & $16.4^{*}$ & 9.0 & $8.7^{*}$ & 6.7 \\
\hline & reference & 4 & 7 & $10.7 *$ & 9.3 & $4.5^{*}$ & 4.2 & $6.0^{*}$ & 5.9 \\
\hline & conditioned & 2 & 7 & 35.2 & 18.0 & $16.0^{*}$ & 6.5 & $10.2 *$ & 5.8 \\
\hline & conditioned & 4 & 6 & $19.3^{*}$ & 6.8 & $6.3^{*}$ & 3.7 & $8.6^{*}$ & 4.6 \\
\hline & collagen/CS & 2 & 8 & 31.5 & 12.2 & $18.4^{*}$ & 7.5 & $10.0^{*}$ & 6.6 \\
\hline & collagen/CS & 4 & 7 & $14.2 *$ & 8.0 & $5.6^{*}$ & 4.2 & $5.7 *$ & 2.7 \\
\hline & simvastatin & 2 & 8 & 38.9 & 19.8 & $28.6^{*}$ & 9.9 & 17.7 & 4.7 \\
\hline & simvastatin & 4 & 6 & $25.6^{*}$ & 4.6 & $9.3 *$ & 3.9 & $6.0^{*}$ & 3.4 \\
\hline & $\begin{array}{l}\text { zoledronic } \\
\text { acid }\end{array}$ & 2 & 7 & $18.1^{*}$ & 8.4 & $23.1^{*}$ & 6.2 & $9.7 *$ & 7.0 \\
\hline & $\begin{array}{l}\text { zoledronic } \\
\text { acid }\end{array}$ & 4 & 7 & $43.2 * \#$ & 17.8 & $23.8 * \#$ & 8.6 & $7.3^{*}$ & 5.4 \\
\hline
\end{tabular}

Significantly different $(p \leq 0.05)$ compared to reference in non- OVX $(*)$ or OVX (\#) rats at the same time point; equal number of animals $(n)$ for all parameters.

\section{Bone-Implant Contact (BIC)}

BIC was comparable between the oestrogen competent groups having received the reference implant or the implant with the conditioned surface both at two and four weeks according to microCT and histomorphometric readouts (Tables 2 and 3). The two corresponding OVX groups were also comparable at both time points. However, they had dramatically reduced BIC compared to intact animals. Structurally these findings correlated to a poor bone template in the long-term oestrogen deprived animals: both in the region adjacent to the implant and the neighbouring region (Tables 2 and 3, Fig. 2).

Two weeks post-implantation neither collagen/ chondroitin sulphate nor zoledronic acid coating had any impact on BIC compared to OVX controls (Tables 2 and 3), while statin coating improved BIC. After four weeks however, no effect related to latter was detectable. At this time point zoledronic acid coated implants displayed a higher BIC than controls, while the BIC of implants having received collagen/chondroitin sulphate coating remained comparable to controls (Tables 2 and 3). Consequently, all oestrogen-deprived osteopenic animals displayed lower BIC than oestrogen-competent animals with the exception of those having received zoledronic acid coated implants. In general BIC was lower in OVX rats after four weeks compared to two weeks, with the exception of the group with zoledronic acid coated implants which displayed a higher BIC at the later time point (Tables 2 and 3).

\section{Cancellous bone mass}

MicroCT analyses demonstrated dramatically reduced cancellous bone volume (BV/TV) and cancellous bone- mineral density (BMD) in all oestrogen-depleted animals two and four weeks post-implantation compared to oestrogen-competent rats irrespective of implant surface treatment (Table 2). However, BV/TV was higher in the group having received zoledronic acid coated implants compared to all other OVX groups after four weeks (Table $2)$. BMD values showed a similar pattern. Analogous to $\mathrm{BIC}$, the amount of cancellous bone decreased in OVX rats between two and four weeks with the exception of the group having received zoledronic acid coated implants, while it remained stable in intact animals (Table 2).

Histomorphometric results (Table 3) confirmed the microCT findings. Oestrogen deprived rats had at both time points irrespective of implant surface treatment lower bone area (BA) values adjacent to the implant. Consistently BA was higher in the group having received zoledronic acid coated implants compared to all other OVX groups after four weeks (Table 3). Moreover, in alignment with the microCT results BA adjacent to the implant decreased in OVX rats between two and four weeks with the exception of the group having received zoledronic acid coated implants, but was stable in intact animals (Table 3). The distant BA neighbouring the tissue area adjacent to the implant showed a slightly different pattern, insofar as all OVX groups displayed at both time points reduced BA compared to non-OVX animals including the zoledronic acid coated implant group with one exception. At the two-week time point, the group which had been exposed to statin coated implants displayed in this region a higher BA (Table 3). However, by four weeks this effect was not detectable anymore and BA was comparable between OVX groups, which was somewhat lower, though not 

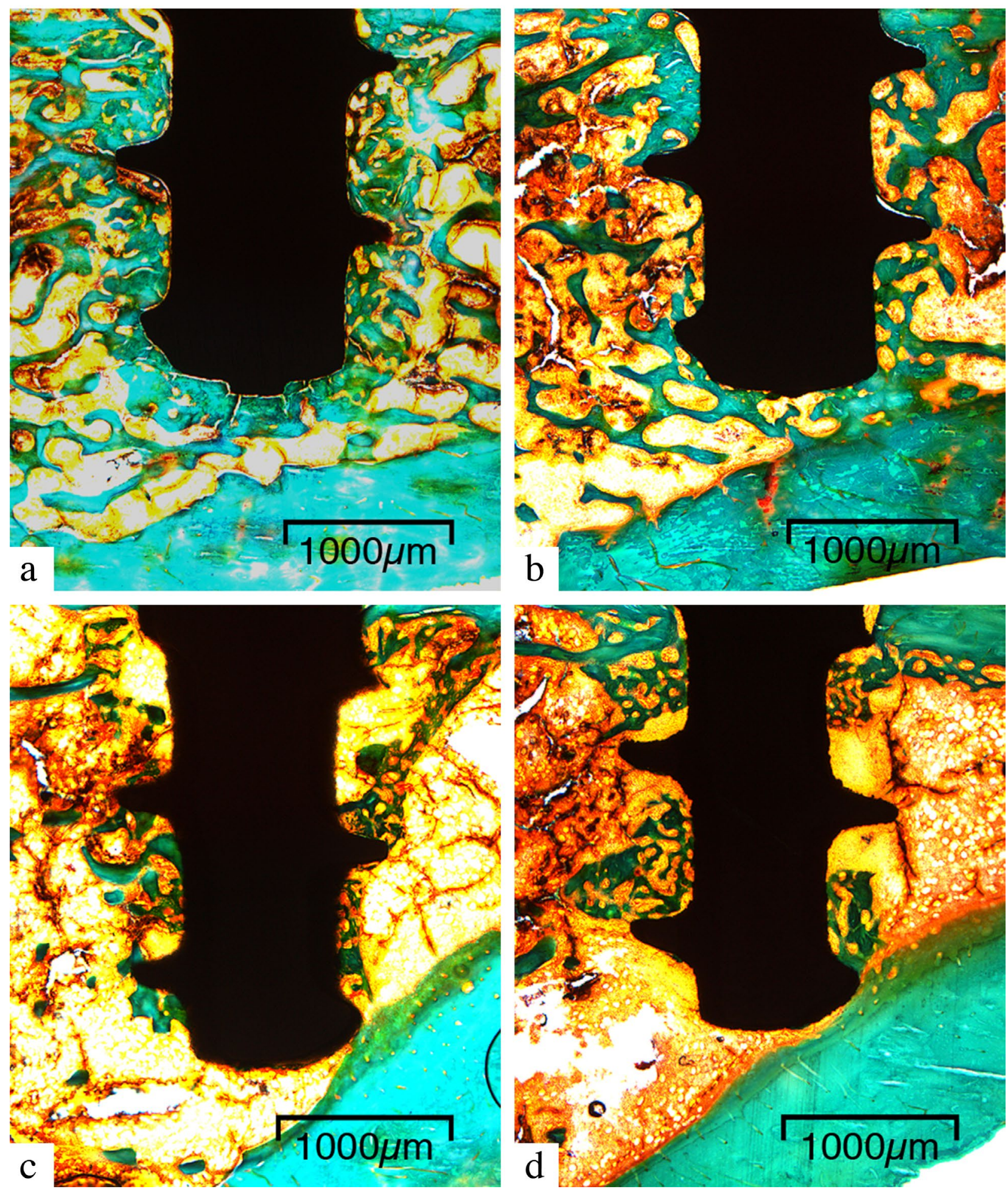

Fig. 3. Histology (Masson-Goldner staining): After 2 weeks, reference implant surfaces in the tibiae of oestrogen competent rats displayed homogenous bone formation within implant threads (a). This zone was remodelled by 4 weeks and the implant integrated in the regular trabecular bone structure (b). The tibiae of OVX rats with zoledronic acid coated implants; also some trabecular structures with partial implant contact were visible after 2 weeks (c), which were also observed after 4 weeks within implant threads (d).

significantly so (with the exception of the statin exposed group), than at two weeks. Overall, BA was higher in the area adjacent to the implant than in the neighbouring distant region (Table 3, Fig. 3).

\section{Fluorochrome marker uptake}

Calcein labels were readily detectable and more pronounced two weeks post-implantation. In addition to the incorporation of fluorochrome labels in the unaffected secondary spongiosa and endosteum at sites of bone formation and mineralisation related to normal bone turnover, a high level of intensive calcein labelling was detectable in peri-implant tissues up to $1 \mathrm{~mm}$ distance from the implant surface. This appeared most pronounced for the collagen/chondroitin sulphate and statin coated surfaces. By four weeks peri-implant label uptake was low. Alizarin, 
a

2 weeks

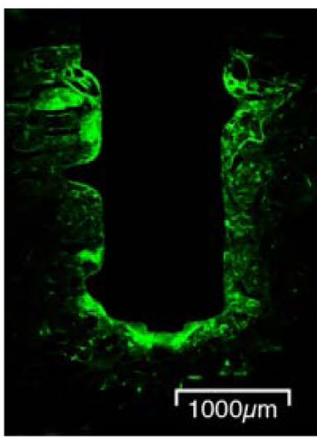

e

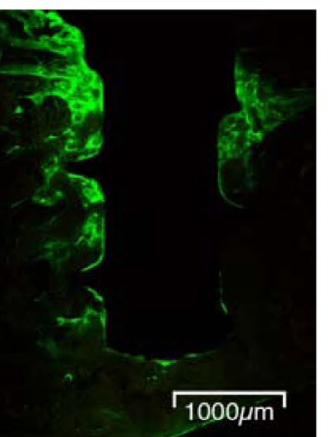

i

$\mathrm{m}$
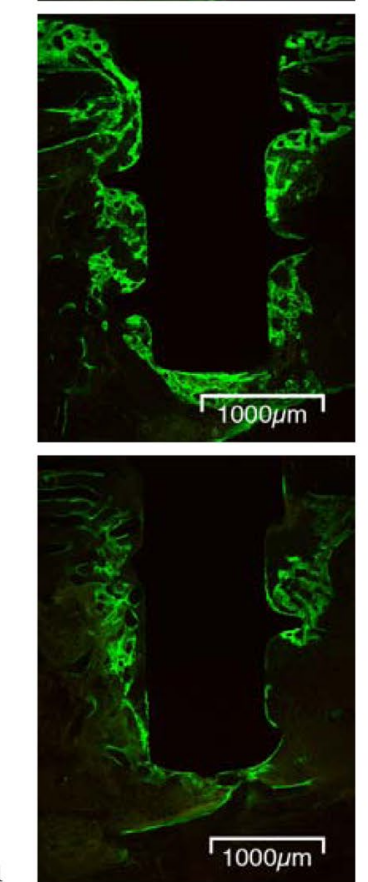

4 weeks
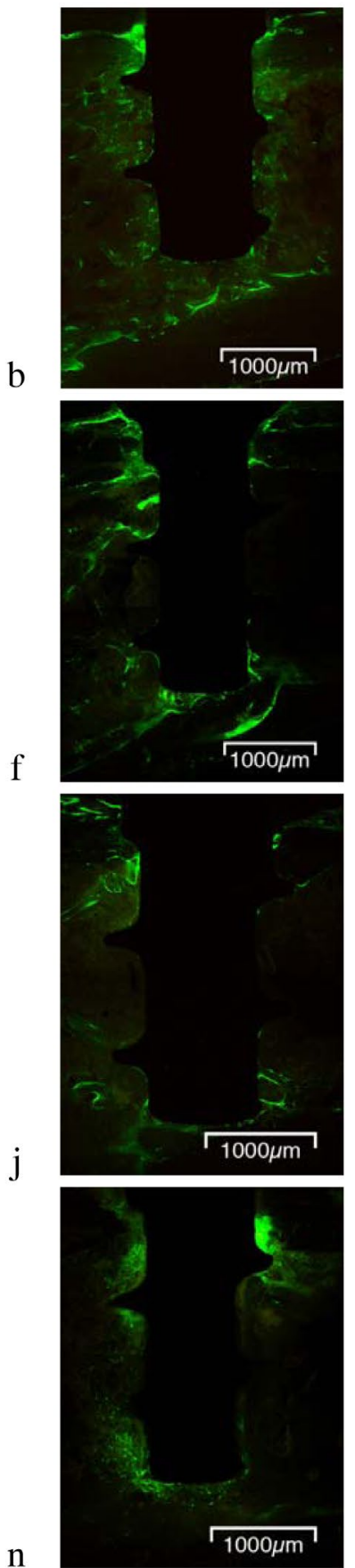

2 weeks
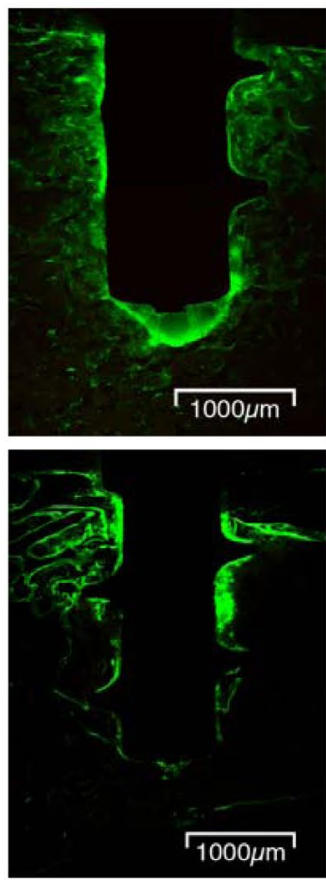

$\mathrm{g}$

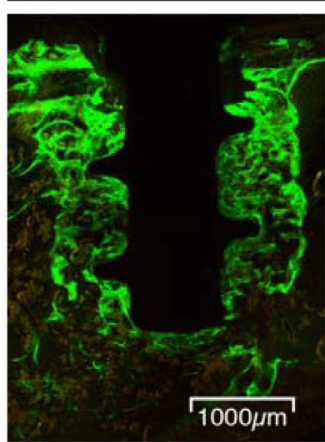

4 weeks

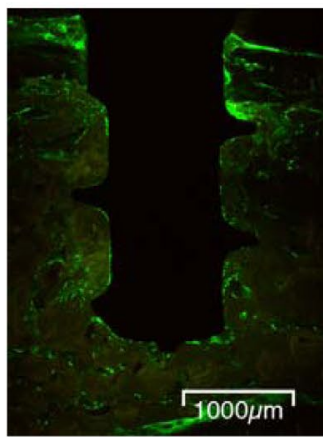

$\mathrm{h}$
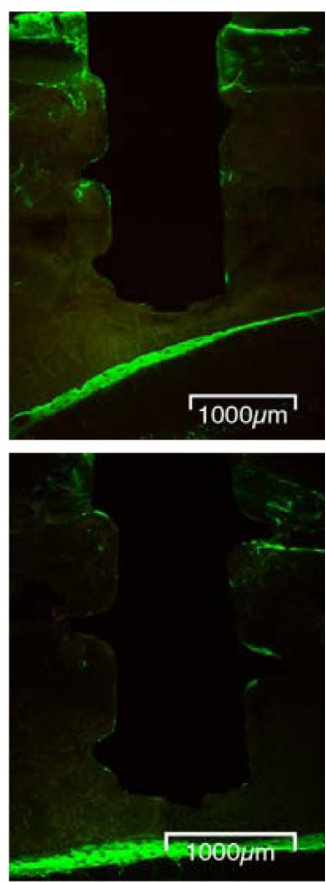

Fig. 4. Fluorescence microscopy: reference implants in oestrogen competent rats $(\mathbf{a}, \mathbf{b})$, and OVX rats $(\mathbf{e}, \mathbf{f})$ two (a, e) and four (b, f) weeks post-surgery; conditioned implants in oestrogen competent $(\mathbf{c}, \mathbf{d})$ and $\operatorname{OVX}(\mathbf{g}, \mathbf{h})$ rats two $(\mathbf{c}, \mathbf{g})$ and four ( $\mathbf{d}, \mathbf{h})$ weeks post-surgery; collagen / chondroitin sulphate coated implants in OVX rats two (i) and four (j) weeks post-surgery; simvastatin coated implant in OVX rats two (k) and four (l) weeks post-surgery, zoledronic acid coated implant in OVX rats two (m) and four (n) weeks post-surgery.

which had been applied earlier than calcein, was generally rarely visible in the peri-implant area at either time point. A marked qualitative difference in peri-implant fluorochrome marker uptake was not noticed between OVX rats and intact controls. (Fig. 4).

\section{Biomechanical properties}

Removal torque was lower in all oestrogen-deprived groups compared to oestrogen-competent groups (Table 4) at both time points. None of the implant surface coatings had any significant impact on removal torque at either time point (Table 4). Removal torque was higher at four weeks in all groups compared to two weeks, reaching significance in the intact groups and the OVX groups exposed to zoledronic acid or collagen/chondroitin coated implants (data not shown). Stiffness was largely comparable between groups irrespective of oestrogen status and implant surface treatment (Table 4). Only the OVX group having received the reference implant displayed decreased stiffness at the two-week time point. Generally, stiffness was somewhat higher at four weeks in all groups reaching significance in most with the exception of the intact group with the conditioned implant surface and the OVX group with the statin coated surface (data not shown).

\section{Correlation between assessed parameters}

Consistent with the above-described findings the correlation analysis showed a significant correlation between various parameters two and four weeks postimplantation: BIC by microCT and histomorphometry showed a significant correlation to adjacent and distant BA by histomorphometry, BV/TV and BMD by microCT and 
Table 4. Results of mechanical testing at two and four weeks.

\begin{tabular}{|c|c|c|c|c|c|c|c|}
\hline \multirow[b]{2}{*}{ Group } & \multirow[b]{2}{*}{ Surface } & \multicolumn{2}{|c|}{ Healing time } & \multicolumn{2}{|c|}{ Removal torque } & \multicolumn{2}{|c|}{ Stiffness } \\
\hline & & [weeks] & $n$ & [Nmm] & SD & {$\left[\mathrm{Nmm} /{ }^{\circ}\right]$} & SD \\
\hline \multirow{4}{*}{$\begin{array}{l}\text { non- } \\
\text { OVX }\end{array}$} & reference & 2 & 8 & $57.0 \#$ & 13.9 & $29.5 \#$ & 2.5 \\
\hline & reference & 4 & 8 & $85.7 \#$ & 21.9 & 31.3 & 3.4 \\
\hline & conditioned & 2 & 8 & $56.0 \#$ & 18.6 & $29.5 \#$ & 3.6 \\
\hline & conditioned & 4 & 8 & $94.7 \#$ & 20.9 & 35.3 & 4.4 \\
\hline \multirow{10}{*}{ OVX } & reference & 2 & 8 & $30.5^{*}$ & 9.6 & $19.2^{*}$ & 10.1 \\
\hline & reference & 4 & 8 & $41.5^{*}$ & 15.5 & 33.3 & 8.2 \\
\hline & conditioned & 2 & 8 & 36.7 & 12.5 & $26.1 *$ & 7.2 \\
\hline & conditioned & 4 & 8 & $43.6^{*}$ & 7.5 & 33.7 & 5.6 \\
\hline & collagen/CS & 2 & 8 & 37.4 & 13.0 & 26.5 & 3.9 \\
\hline & collagen/CS & 4 & 8 & $50.4 *$ & 9.8 & 36.7 & 6.9 \\
\hline & simvastatin & 2 & 8 & $32.0 *$ & 12.6 & 22.1 & 7.1 \\
\hline & simavstatin & 4 & 8 & $44.2 *$ & 13.6 & 28.5 & 7.1 \\
\hline & zoledronic acid & 2 & 8 & $29.8 *$ & 10.5 & 24.1 & 6.0 \\
\hline & zoledronic acid & 4 & 8 & $52.9 *$ & 17.0 & 31.0 & 4.3 \\
\hline
\end{tabular}

Significantly different $(p \leq 0.05)$ compared to reference in non- OVX $(*)$ or OVX $(\#)$ rats at the same time point; equal number of animals $(n)$ for both parameters.

removal torque. The results of the stiffness test correlated to removal torque at both time points and 2 weeks postimplantation to BV/TV and BMD (Table 5).

\section{Discussion}

Several previous studies have analysed the impact of conditioning or drug coating of implant surfaces in animal models of osseointegration (Buser et al., 2004; Rammelt et al., 2007; Wermelin et al., 2008b). Increased peri-implant bone formation and improved biomechanical characteristics have been demonstrated for such surface treatments in some cases. An improvement of osseointegration would be especially beneficial in compromised osseous situations such as osteoporosis (Bernhardt et al., 2005), which is characterised by a systemic deterioration of bone mass and microarchitecture (Rachner et al., 2011). Studies analysing implant osseointegration in osteoporotic patients yielded differential results. Whereas some studies report increased implant loss rates for osteoporotic patients (Moy et al., 2005; Alsaadi et al., 2007), others did not observe increased implant loss rates for these patients (Dvorak et al., 2011). A systematic review describes the level of evidence for studies on this matter as multiple case-control studies (Bornstein et al., 2009). In the present study, we analysed the osseointegration of a number of different conditioned or coated implants. Some of these surfaces have previously been described to display increased osseointegration in animal models under compromised osteoporotic conditions. We utilised aged rats, which were oestrogen-deprived by ovariectomy, as a standard model for the simulation of post-menopausal osteoporosis
(Thompson et al., 1995). Following ovariectomy, bone resorption exceeds bone formation, increasing bone turnover and inducing rapid cancellous bone loss resulting in a severely rarefied trabecular network within three months (Jee and Yao, 2001). We placed the implants three months post-ovariectomy into the proximal tibia metaphysis as a well characterised skeletal site for sexhormone deprival induced bone loss. As expected, both microCT and histological evaluation confirmed a severely compromised cancellous bone network in the proximal tibia of those aged animals.

The first implant modification for improvement of implant osseointegration we tested was surface conditioning as a means to modify the physicochemical characteristics of an implant. Histomorphometric and micro-CT measurements of BIC and bone volume served to quantify peri-implant bone formation. The correlation of histological and micro-computed tomographic data for the analysis of BIC and bone volume has been analysed in an earlier study applying synchrotron radiation (Bernhardt et al., 2012). The conditioning by hydroxide ions influences surface charge, hydrophilicity and the homogeneity of the initial protein layer (Tugulu et al., 2010). Various animal studies utilising non-osteoporotic conditions have analysed mechanics and histomorphometry of such conditioned implants, and demonstrated increased bone formation and removal torque values indicating improved osseointegration (Ferguson et al., 2006; Calvo-Guirado et al., 2010; Stadlinger et al., 2012). However, in our setting, we observed - neither in osteoporotic oestrogen deprived nor in non-osteoporotic oestrogen-competent animals an increase of bone-implant contact or an improvement of biomechanical properties in comparison to reference 
Table 5. Inter-group-correlation analysis. Pearson correlation coefficient and two-tailed $p$ values (in brackets) are shown for each parameter and time point.

\begin{tabular}{|c|c|c|c|c|c|c|c|c|c|}
\hline Time & Parameter & $\begin{array}{c}\text { BIC } \\
\text { (Hist.) }\end{array}$ & $\begin{array}{c}\text { BA } \\
\text { adjacent }\end{array}$ & $\begin{array}{c}\text { BA } \\
\text { distant }\end{array}$ & $\begin{array}{c}\text { Removal } \\
\text { torque }\end{array}$ & Stiffness & $\begin{array}{c}\text { BIC } \\
\text { (MicroCT) }\end{array}$ & BV/TV & BMD \\
\hline \multirow{16}{*}{$\begin{array}{c}2 \\
\text { weeks }\end{array}$} & BIC (Hist.) & 1 & $0.685^{* *}$ & $0.638^{* *}$ & $0.382 * *$ & 0.224 & $0.538 * *$ & $0.476^{* *}$ & $0.473^{* *}$ \\
\hline & & & $(0.000)$ & $(0.000)$ & $(0.005)$ & $(0.111)$ & $(0.000)$ & $(0.001)$ & $(0.001)$ \\
\hline & BA adjacent & $0.685^{* *}$ & 1 & $0.910 * *$ & $0.406 * *$ & 0.153 & $0.617 * *$ & $0.617 * *$ & $0.616^{* *}$ \\
\hline & & $(0.000)$ & & $(0.000)$ & $(0.003)$ & $(0.278)$ & $(0.000)$ & $(0.000)$ & $(0.000)$ \\
\hline & BA distant & $0.638 * *$ & $0.910^{* *}$ & 1 & $0.318^{*}$ & 0.132 & $0.687 * *$ & $0.652 * *$ & $0.655^{* *}$ \\
\hline & & $(0.000)$ & $(0.000)$ & & $(0.021)$ & $(0.351)$ & $(0.000)$ & $(0.000)$ & $(0.000)$ \\
\hline & Removal torque & $0.382 * *$ & $0.406^{* *}$ & $0.318^{*}$ & 1 & $0.601 * *$ & $0.490 * *$ & $0.521 * *$ & $0.507 * *$ \\
\hline & & $(0.005)$ & $(0.003)$ & $(0.021)$ & & $(0.000)$ & $(0.001)$ & $(0.000)$ & $(0.000)$ \\
\hline & Stiffness & 0.224 & 0.153 & 0.132 & $0.601 * *$ & 1 & 0.275 & $0.353^{*}$ & $0.294 *$ \\
\hline & & $(0.111)$ & $(0.278)$ & $(0.351)$ & $(0.000)$ & & $(0.067)$ & $(0.012)$ & $(0.036)$ \\
\hline & BIC (MicroCT) & $0.538^{* *}$ & $0.617 * *$ & $0.687 * *$ & $0.490 * *$ & 0.275 & 1 & $0.962 * *$ & $0.973 * *$ \\
\hline & & $(0.000)$ & $(0.000)$ & $(0.000)$ & $(0.001)$ & $(0.067)$ & & $(0.000)$ & $(0.000)$ \\
\hline & $\mathrm{BV} / \mathrm{TV}$ & $0.476^{* *}$ & $0.617 * *$ & $0.652 * *$ & $0.521 * *$ & $0.353 *$ & $0.962 * *$ & 1 & $0.985^{* *}$ \\
\hline & & $(0.001)$ & $(0.000)$ & $(0.000)$ & $(0.000)$ & $(0.012)$ & $(0.000)$ & & $(0.000)$ \\
\hline & BMD & $0.473 * *$ & $0.616^{* *}$ & $0.655^{* *}$ & $0.507 * *$ & $0.294 *$ & $0.973 * *$ & $0.985^{* *}$ & 1 \\
\hline & & $(0.001)$ & $(0.000)$ & $(0.000)$ & $(0.000)$ & $(0.036)$ & $(0.000)$ & $(0.000)$ & \\
\hline \multirow{16}{*}{$\begin{array}{c}4 \\
\text { weeks }\end{array}$} & BIC (Hist.) & 1 & $0.847 * *$ & $0.700 * *$ & $0.570 * *$ & -0.056 & $0.807 * *$ & $0.764 * *$ & $0.786^{* *}$ \\
\hline & & & $(0.000)$ & $(0.000)$ & $(0.000)$ & $(0.714)$ & $(0.000)$ & $(0.000)$ & $(0.000)$ \\
\hline & BA adjacent & $0.847 * *$ & 1 & $0.893 * *$ & $0.615^{* *}$ & 0.029 & $0.867 * *$ & $0.817^{* *}$ & $0.844 * *$ \\
\hline & & $(0.000)$ & & $(0.000)$ & $(0.000)$ & $(0.849)$ & $(0.000)$ & $(0.000)$ & $(0.000)$ \\
\hline & BA distant & $0.700 * *$ & $0.893 * *$ & 1 & $0.600 * *$ & 0.094 & $0.764 * *$ & $0.765 * *$ & $0.774 * *$ \\
\hline & & $(0.000)$ & $(0.000)$ & & $(0.000)$ & $(0.536)$ & $(0.000)$ & $(0.000)$ & $(0.000)$ \\
\hline & Removal torque & $0.570 * *$ & $0.615 * *$ & $0.600 * *$ & 1 & $0.316^{*}$ & $0.614 * *$ & $0.695 * *$ & $0.703 * *$ \\
\hline & & $(0.000)$ & $(0.000)$ & $(0.000)$ & & $(0.018)$ & $(0.000)$ & $(0.000)$ & $(0.000)$ \\
\hline & Stiffness & -0.056 & 0.029 & 0.094 & $0.316^{*}$ & 1 & -0.085 & -0.079 & -0.070 \\
\hline & & $(0.714)$ & $(0.849)$ & $(0.536)$ & $(0.018)$ & & $(0.568)$ & $(0.584)$ & $(0.630)$ \\
\hline & BIC (MicroCT) & $0.807 * *$ & $0.867 * *$ & $0.764 * *$ & $0.614 * *$ & -0.085 & 1 & $0.970 * *$ & $0.978 * *$ \\
\hline & & $(0.000)$ & $(0.000)$ & $(0.000)$ & $(0.000)$ & $(0.568)$ & & $(0.000)$ & $(0.000)$ \\
\hline & $\mathrm{BV} / \mathrm{TV}$ & $0.764 * *$ & $0.817 * *$ & $0.765^{* *}$ & $0.695^{* *}$ & -0.079 & $0.970 * *$ & 1 & $0.992 * *$ \\
\hline & & $(0.000)$ & $(0.000)$ & $(0.000)$ & $(0.000)$ & $(0.584)$ & $(0.000)$ & & $(0.000)$ \\
\hline & BMD & $0.786^{* *}$ & $0.844 * *$ & $0.774 * *$ & $0.703 * *$ & -0.070 & $0.978 * *$ & $0.992 * *$ & 1 \\
\hline & & $(0.000)$ & $(0.000)$ & $(0.000)$ & $(0.000)$ & $(0.630)$ & $(0.000)$ & $(0.000)$ & \\
\hline
\end{tabular}

* The correlation was statistically significant at a level of 0.05 (two tailed). ** The correlation was statistically significant at a level of 0.01 (two tailed).

surfaces. This difference might relate to a diminishing pool of osteoprogenitor cells in those ageing animals (Pei et al., 2003). Next, we tested whether implant coating with components of the bone extracellular matrix (ECM) would stimulate bone osseointegration in our compromised setting (Stadlinger et al., 2009a). Collagen type I is the main structural component of the bone organic ECM and has been previously demonstrated to favour the adhesion of osteoblastic cells (Becker et al., 2002). In addition, the application of glycosaminoglycans such as chondroitin sulphate (CS) influences the adhesion, proliferation and differentiation of osteoblasts (Bierbaum et al., 2006;
Douglas et al., 2007). Accordingly, the suitability of collagen/CS coated implant surfaces has been assessed in various in vitro and in vivo studies. In minipigs, collagen/CS coated implants showed improved implant osseointegration, compared to pure collagen coatings (Stadlinger et al., 2008). Such coated implants, displayed in mandibular and maxillary bone, increased BIC compared to sandblasted, acid-etched implants 4 weeks postimplantation (Stadlinger et al., 2009a; Stadlinger et al., 2011). In addition, Rammelt et al. examined collagen/CS coated intramedullary nails in tibiae of 90 days old intact male rats and showed increased bone formation and bone 
remodelling in comparison to uncoated surfaces (Rammelt et al., 2006). In our study in older female rats, collagen/ CS coated surfaces did not show significant differences in mechanics and peri-implant bone formation in comparison to uncoated surfaces. Increased values in mechanical tests did not reach a level of significance. This is somewhat unexpected as the promising results obtained previously in large animal models suggested that a pronounced positive effect might also be detectable under osteoporotic conditions. Yet, our results indicate that in a setting of severely reduced bony template and a presumably reduced osteoblastic precursor pool such surface coatings cannot exert their beneficial effect.

We also tested a principle that has been previously suggested to impact bone formation by stimulating bone morphogenetic proteins (BMPs). It is well established that the differentiation of osteoblastic cells is increased by BMPs (Mundy et al., 1999) and that this is relevant to implant osseointegration. Different studies have suggested that BMP expression can be stimulated by statins (Oxlund et al., 2001; Skoglund et al., 2002). Clinically, statins are administered to decrease high cholesterol levels through inhibition of the enzyme HMG-CoA reductase which is involved in the cholesterol synthesis. Induction of an osteoanabolic effect occurs only at higher dosages than required for cholesterol inhibition (Moriyama et al., 2010). In addition, a putative inhibition of osteoclast activation has been proposed (Moriyama et al., 2010). Statins have been applied in various animal models of osseointegration and improved implant integration rates in non-compromised (Ayukawa et al., 2010; Moriyama et al., 2010) and osteoporotic animal models (Du et al., 2009) have been reported. Local application of fluvastatin increased peri-implant bone formation in the tibial bone of oestrogen competent growing ten-week-old female rats, (Moriyama et al., 2010). In addition, systemic high dose treatment improved peri-implant bone deposition in the implant carrying tibial medullar cavity of intact skeletally mature 30-week-old female rats (Ayukawa et al., 2010). Moreover, systemic application of simvastatin to 5-month-old rats, which had been ovariectomised two months prior to implant placement, also enhanced osseointegration (Du et al., 2009). We used in our study older animals than any previous study and placed implants after a more extended oestrogen deprival induced bone loss period, while the examined implant healing intervals were comparable to other studies. In comparison to Du et al. (2009), cancellous bone loss was far more pronounced in our study. In addition, implant insertion was in the present study mono-cortical while Du et al. performed bi-cortical insertion. Since the successful local application of statins has been demonstrated to depend on an effective drug delivery system, like chitosan, PGA (Moriyama et al., 2010) or methylcellulose gels (Thylin et al., 2002), we have utilised chitosan in the present study. In accordance with previous studies, we observed a transient increase in BIC and the amount of peri-implant bone in the group that had received statin coated implants. Consistently, fluorochrome marker uptake appeared in the peri-implant area elevated two weeks post-implantation compared to other surfaces. However, these changes did not translate into improved biomechanical readouts and at the later time-point no impact of the statin coating was detectable any more. Since we consider our animal model to more faithfully mimic severely compromised osteoporotic settings, we conclude that the ability of locally released statins to improve osseointegration under such conditions is limited.

Finally, to complete the spectrum of implant surface modifications that are known to impact bone metabolism and thus may impact osseointegration we tested an anti-resorptive principle. Bisphosphonates are potent anti-resorptive drugs that primarily target osteoclasts (Abtahi et al., 2010). Clinically, bisphosphonates are administered intravenously in patients suffering from bone metastasis of malignant tumours. Lower doses of various bisphosphonates are applied by infrequent oral or intravenous injection for various bone fragility conditions including osteoporosis. In addition to systemic treatments, local release from implant surfaces has already been tested previously in preclinical settings (Gao et al., 2009; Wermelin et al., 2008b). Zoledronic acid is a potent bisphosphonate with a high affinity to mineralised bone (Li and Davis, 2003). In the present study zoledronic acid coated surfaces were the only implants that lead to a significant increase in BIC from two to four weeks. The animals that had received those implants displayed an increase in the amount of bone surrounding the implant at the end of the study. Consistently, maintenance of a higher amount of fluorochrome labelled peri-implant bone was visible at the end of the study compared to other groups. Since bone resorption and bone formation are uncoupled during a repair process like osseointegration, bone formation can commence despite the presence of the anti-resorptive bisphosphonate opposed to situations in which bone resorption and bone formation are coupled such as normal adult bone remodelling (Baron and Kneissel, 2013). However, the apparently increased fluorochrome marker uptake does not necessarily reflect increased bone formation compared to the other groups, but could simply reflect the maintenance of the newly formed bone by antiresorptive action, while this bone was rapidly removed in the other groups in the absence of such a principle. As mentioned above, various previous studies analysed the application of bisphosphonates on osseointegration in animals. Consistent with our results, improvement of the amount of peri-implant bone formation was also detected in OVX rats after 8 weeks (Gao et al., 2009). Of note compared to our study, Gao et al. operated younger rats, which however also underwent implant placement in the tibial medullar cavity three months post-OVX. Three months post-implantation, bone area and BIC were found to be doubled in animals carrying implants with bisphosphonate coatings on a hydroxyapatite implant surface layer (Gao et al., 2009). Our findings are overall consistent with other studies, showing increased implant fixations for bisphosphonate coatings using different carriers and displaying different drug release kinetics (Andersson et al., 2010; Peter et al., 2006), though involved. Wermelin et al. analysed the surface release of bisphosphonates, showing that one third of the coating was released within 4 weeks (Wermelin et al., 2008a). Gao et 
al. demonstrated zoledronic acid coating up to 21 days after implantation (Gao et al., 2009). In the present study, analyses of the release kinetics of statin and zoledronic acid coatings revealed a surface release restricted to 7-13 days, indicating that this local relatively short-term release was sufficient to induce longer-term effects as detected up to one month. Though the bisphosphonate coating emerged in this setting of severely osteoporotic and compromised bone as the most promising principle, safety aspects have to be considered. Clinically, the intra-oral application of bisphosphonates needs to address the aspect of oral necrosis of the jaw (ONJ). The ONJ has been described in various studies for the systemic application of high dose bisphosphonates in cancer patients (Marx, 2003; Ruggiero et al., 2009). Abtahi et al. addressed this question and describes that no animal study observed to date necrotic bone around bisphosphonate coated implants (Abtahi et $a l ., 2010)$. They further examined the infiltration depth of surface bound bisphosphonates into the peri-implant bone, measuring a maximum distance of less than $1 \mathrm{~mm}$ (Abtahi et al., 2010; Wermelin et al., 2008b). A translation of the mentioned animal studies to the human situation is limited by the fact that implants healed submerged. A loaded dental implant in humans, however, is exposed to the oral cavity and oral bacteria. A further consideration is long-term implant stability, which requires continuous bone remodelling in order to preserve osseointegration (Roberts et al., 1992). To date, first results in humans receiving zoledronic acid coated implants indicate increased stability after 6 months of submerged healing (Abtahi et al., 2012). Further investigations are required to assess how implants from which bisphosphonates have been released respond to remodelling processes following implant loading. Limiting release of the drug to a shorter time window, like in the present study, may be one way to limit the amount of peri-implant bone that is exposed to the anti-resorptive principle, allowing hence for a faster recovery of remodelling based bone turnover.

In summary, the present study assessed the impact of implant surface modifications, which have resulted previously in improved osseointegration in preclinical settings, in an animal model of severe osteoporosis. In this setting, most modifications did not yield an appreciable improvement, though simvastatin coating had a transient positive impact on the amount of peri-implant bone and the amount of bone-implant contact. Only zoledronic acid coating improved osseointegration at the end of the study, suggesting that such coatings may be of interest in the settings of severely compromised bone template. Further studies are, however, required to demonstrate the long-term success of such coated implants.

\section{Acknowledgements}

This study was funded by Thommen Medical AG. The authors thank Peter Ingold, Marcel Merdes, Marco Pegurri, Renzo Schumpf, Andrea Venturiere, and Anne Studer for their contribution to this study. We also thank the project partners of the SFB Transregio 67 of the DFG (German Research Foundation), especially projects $\mathrm{A} 3$ and $\mathrm{A} 2$.

\section{References}

Abtahi J, Tengvall P, Aspenberg P(2010) Bisphosphonate coating might improve fixation of dental implants in the maxilla: a pilot study. Int J Oral Maxillofac Surg 39: 673677.

Abtahi J, Tengvall P, Aspenberg P (2012) A bisphosphonate-coating improves the fixation of metal implants in human bone. A randomized trial of dental implants. Bone 50: 1148-1151.

Alsaadi G, Quirynen M, Komarek A, van Steenberghe D (2007) Impact of local and systemic factors on the incidence of oral implant failures, up to abutment connection. J Clin Periodontol 34: 610-617.

Andersson T, Agholme F, Aspenberg P, Tengvall P (2010) Surface immobilized zoledronate improves screw fixation in rat bone: a new method for the coating of metal implants. Journal of materials science. Mater Med 21: 3029-3037.

Ayukawa Y, Ogino Y, Moriyama Y, Atsuta I, Jinno Y, Kihara M, Tsukiyama Y, Koyano K (2010) Simvastatin enhances bone formation around titanium implants in rat tibiae. J Oral Rehabil 37: 123-130.

Baron R, Kneissel M (2013) WNT signaling in bone homeostasis and disease: from human mutations to treatments. Nat Med 19: 179-192.

Becker D, Geissler U, Hempel U, Bierbaum S, Scharnweber D, Worch H, Wenzel KW (2002) Proliferation and differentiation of rat calvarial osteoblasts on type I collagen-coated titanium alloy. J Biomed Mater Res 59: 516-527.

Bernhardt R, van den Dolder J, Bierbaum S, Beutner R, Scharnweber D, Jansen J, Beckmann F, Worch H (2005) Osteoconductive modifications of Ti-implants in a goat defect model: characterization of bone growth with SR muCT and histology. Biomaterials 26: 3009-3019.

Bernhardt R, Kuhlisch E, Schulz MC, Eckelt U, Stadlinger B (2012) Comparison of bone-implant contact and bone-implant volume between 2D-histological sections and 3D-SRmicroCT slices. Eur Cells Mater 23: 237-248.

Bierbaum S, Douglas T, Hanke T, Scharnweber D, Tippelt S, Monsees TK, Funk RH, Worch H (2006) Collageneous matrix coatings on titanium implants modified with decorin and chondroitin sulfate: characterization and influence on osteoblastic cells. J Biomed Mater Res A 77: 551-562.

Bornstein MM, Cionca N, Mombelli A(2009) Systemic conditions and treatments as risks for implant therapy. Int J Oral Maxillofac Implants 24 Suppl: 12-27.

Branemark PI, Hansson BO, Adell R, Breine U, Lindstrom J, Hallen O, Ohman A (1977) Osseointegrated implants in the treatment of the edentulous jaw. Experience from a 10-year period. Scand J Plast Reconstr Surg Suppl 16: 1-132.

Buser D, Broggini N, Wieland M, Schenk RK, Denzer AJ, Cochran DL, Hoffmann B, Lussi A, Steinemann SG (2004) Enhanced bone apposition to a chemically modified SLA titanium surface. J Dent Res 83: 529-533.

Butz F, Aita H, Wang CJ, Ogawa T (2006) Harder and stiffer bone osseointegrated to roughened titanium. J Dent Res 85: 560-565. 
Calvo-Guirado JL, Ortiz-Ruiz AJ, Negri B, Lopez-Mari L, Rodriguez-Barba C, Schlottig F (2010) Histological and histomorphometric evaluation of immediate implant placement on a dog model with a new implant surface treatment. Clin Oral Implants Res 21: 308-315.

Davies JE (1998) Mechanisms of endosseous integration. Int J Prosthodont 11:391-401.

Donath K, Breuner G (1982) A method for the study of undecalcified bones and teeth with attached soft tissues. The Sage-Schliff (sawing and grinding) technique. J Oral Pathol 11: 318-326.

Douglas T, Heinemann S, Mietrach C, Hempel U, Bierbaum S, Scharnweber D, Worch H (2007) Interactions of collagen types I and II with chondroitin sulfates A-C and their effect on osteoblast adhesion. Biomacromolecules 8: 1085-1092.

Du Z, Chen J, Yan F, Xiao Y (2009) Effects of Simvastatin on bone healing around titanium implants in osteoporotic rats. Clin Oral Implants Res 20: 145-150.

Dvorak G, Arnhart C, Heuberer S, Huber CD, Watzek G, Gruber R (2011) Peri-implantitis and late implant failures in postmenopausal women: a cross-sectional study. J Clin Periodontol 38: 950-955.

Esposito M, Hirsch JM, Lekholm U, Thomsen P (1998) Biological factors contributing to failures of osseointegrated oral implants. (II). Etiopathogenesis. Eur J Oral Sci 106: 721-764.

Ferguson SJ, Broggini N, Wieland M, de Wild M, Rupp F, Geis-Gerstorfer J, Cochran DL, Buser D (2006) Biomechanical evaluation of the interfacial strength of a chemically modified sandblasted and acid-etched titanium surface. J Biomedi Mater Res A,78: 291-297.

Gallez B, Osinski P, Adline J, Dumont P (1988) Rapid and precise micro-methods for quantitating active components in commercial bone scintigraphy kits - II. Diphosphonates. Int J Rad Appl Instrum A 39: 1011-1014.

Gao Y, Luo E, Hu J, Xue J, Zhu S, Li J (2009) Effect of combined local treatment with zoledronic acid and basic fibroblast growth factor on implant fixation in ovariectomized rats. Bone 44: 225-232.

Holahan CM, Koka S, Kennel KA, Weaver AL, Assad DA, Regennitter FJ, Kademani D (2008) Effect of osteoporotic status on the survival of titanium dental implants. Int J Oral Maxillofac Implants 23: 905-910.

Jee WS, Yao W (2001) Overview: animal models of osteopenia and osteoporosis. J Musculoskel Neuronal Interact 1: 193-207.

Jeffcoat M (2005) The association between osteoporosis and oral bone loss. J Periodontol 76: 2125-2132.

Junker R, Dimakis A, Thoneick M, Jansen JA (2009) Effects of implant surface coatings and composition on bone integration: a systematic review. Clin Oral Implants Res 20 Suppl 4: 185-206.

Li EC, Davis LE (2003) Zoledronic acid: a new parenteral bisphosphonate. Clin Ther 25: 2669-2708.

Martin W, Lewis E, Nicol A (2009) Local risk factors for implant therapy. Int J Oral Maxillofac Implants 24 Suppl: $28-38$.

Marx RE (2003) Pamidronate (Aredia) and zoledronate (Zometa) induced avascular necrosis of the jaws: a growing epidemic. J Oral Maxillofac Surg 61: 1115-1117.
Moriyama Y, Ayukawa Y, Ogino Y, Atsuta I, Todo M, Takao Y, Koyano K (2010) Local application of fluvastatin improves peri-implant bone quantity and mechanical properties: a rodent study. Acta Biomater 6: 1610-1618.

Moy PK, Medina D, Shetty V, Aghaloo TL (2005) Dental implant failure rates and associated risk factors. Int J Oral Maxillofac Implants 20: 569-577.

Mundy G, Garrett R, Harris S, Chan J, Chen D, Rossini G, Boyce B, Zhao M, Gutierrez G (1999) Stimulation of bone formation in vitro and in rodents by statins. Science 286: 1946-1949.

Oxlund H, Dalstra M, Andreassen TT (2001) Statin given perorally to adult rats increases cancellous bone mass and compressive strength. Calcif Tiss Int 69: 299-304.

Pei W, Bellows CG, Elsubeihi ES, Heersche JN (2003) Effect of ovariectomy on dexamethasone- and progesterone-dependent osteoprogenitors in vertebral and femoral rat bone cell populations. Bone 33:822-830.

Peter B, Gauthier O, Laib S, Bujoli B, Guicheux J, Janvier P, van Lenthe GH, Muller R, Zambelli PY, Bouler JM, Pioletti DP (2006) Local delivery of bisphosphonate from coated orthopedic implants increases implants mechanical stability in osteoporotic rats. J Biomed Mater Rest A 76: 133-143.

Rachner TD, Khosla S, Hofbauer LC (2011) Osteoporosis: now and the future. Lancet 377: 1276-1287.

Rammelt S, Illert T, Bierbaum S, Scharnweber D, Zwipp H, Schneiders W (2006) Coating of titanium implants with collagen, RGD peptide and chondroitin sulfate. Biomaterials 27: 5561-5571.

Rammelt S, Heck C, Bernhardt R, Bierbaum S, Scharnweber D, Goebbels J, Ziegler J, Biewener A, Zwipp H (2007) In vivo effects of coating loaded and unloaded Ti implants with collagen, chondroitin sulfate, and hydroxyapatite in the sheep tibia. J Orthop Res 25: 1052-1061.

Rebaudi A, Koller B, Laib A, Trisi P (2004) Microcomputed tomographic analysis of the peri-implant bone. Int J Periodontics Restorative Dent 24: 316-325.

Roberts WE, Simmons KE, Garetto LP, DeCastro RA (1992) Bone physiology and metabolism in dental implantology: risk factors for osteoporosis and other metabolic bone diseases. Implant Dent 1: 11-21.

Ruggiero SL, Dodson TB, Assael LA, Landesberg R, Marx RE, Mehrotra B (2009) American Association of Oral and Maxillofacial Surgeons position paper on bisphosphonate-related osteonecrosis of the jaws - 2009 update. J Oral Maxillofac Surg 67: 2-12.

Schindeler A, McDonald MM, Bokko P, Little DG (2008) Bone remodeling during fracture repair: The cellular picture. Semin Cell Develop Biol 19: 459-466.

Sennerby L, Meredith N (2008) Implant stability measurements using resonance frequency analysis: biological and biomechanical aspects and clinical implications. Periodontol 2000 47: 51-66.

Skoglund B, Forslund C, Aspenberg P (2002) Simvastatin improves fracture healing in mice. $\mathrm{J}$ Bone Miner Res 17: 2004-2008.

Stadlinger B, Pilling E, Mai R, Bierbaum S, Berhardt R, Scharnweber D, Eckelt U (2008) Effect of biological implant surface coatings on bone formation, applying 
collagen, proteoglycans, glycosaminoglycans and growth factors. J Mater Sci Mater Med 19: 1043-1049.

Stadlinger B, Bierbaum S, Grimmer S, Schulz MC, Kuhlisch E, Scharnweber D, Eckelt U, Mai R (2009a) Increased bone formation around coated implants. J Clin Periodontol 36: 698-704.

Stadlinger B, Lode AT, Eckelt U, Range U, Schlottig F, Hefti T, Mai R (2009b) Surface-conditioned dental implants: an animal study on bone formation. J Clin Periodontol 36: 82-891.

Stadlinger B, Hintze V, Bierbaum S, Moller S, Schulz MC, Mai R, Kuhlisch E, Heinemann S, Scharnweber D, Schnabelrauch M, Eckelt U (2011) Biological functionalization of dental implants with collagen and glycosaminoglycans-A comparative study. J Biomed Mater Res B, in press.

Stadlinger B, Ferguson SJ, Eckelt U, Mai R, Lode AT, Loukota R, Schlottig F (2012) Biomechanical evaluation of a titanium implant surface conditioned by a hydroxide ion solution. Br J Oral Maxillofac Surg 50: 74-79.

Thompson DD, Simmons HA, Pirie CM, Ke HZ (1995) FDA Guidelines and animal models for osteoporosis. Bone 17: $125 \mathrm{~S}-133 \mathrm{~S}$.

Thylin MR, McConnell JC, Schmid MJ, Reckling RR, Ojha J, Bhattacharyya I, Marx DB, Reinhardt RA (2002) Effects of simvastatin gels on murine calvarial bone. J Periodontol 73: 1141-1148.

Tugulu S, Lowe K, Scharnweber D, Schlottig F (2010) Preparation of superhydrophilic microrough titanium implant surfaces by alkali treatment. J Mater Sci Mater Med 21: 2751-2763.

Wactawski-Wende J, Hausmann E, Hovey K, Trevisan M, Grossi S, Genco RJ (2005) The association between osteoporosis and alveolar crestal height in postmenopausal women. J Periodontol 76: 2116-2124.

Wermelin K, Tengvall P, Aspenberg P (2007) Surfacebound bisphosphonates enhance screw fixation in rats - increasing effect up to 8 weeks after insertion. Acta Orthopaed 78: 385-392.

Wermelin K, Aspenberg P, Linderback P, Tengvall P (2008a) Bisphosphonate coating on titanium screws increases mechanical fixation in rat tibia after two weeks. J Biomed Mater Res A 86: 220-227.

Wermelin K, Suska F, Tengvall P, Thomsen P, Aspenberg P (2008b) Stainless steel screws coated with bisphosphonates gave stronger fixation and more surrounding bone. Histomorphometry in rats. Bone 42: 365-371.

\section{Discussion with Reviewers}

Reviewer I: Which animal model would you prefer if you would repeat the experiment in a large animal model? What differences to the presented approach would you expect? Which size of implants would you choose? The larger size of implants would lead to an increased load of bioactive factors. Could this improve results?

Authors: A possible large animal model would be minipigs. Ovarectomy-induced oestrogen deficiency has been shown to manifest stronger in primiparous as compared to nulliparous minipigs (Scholz-Ahrens et al., 1996, additional reference). Supplementary calcium deficient diet and glucocorticoid application, however, has been able to induce osteopenia in nulliparous (ScholzAhrens et al., 2007, additional reference). The advantage would be the placement of clinically applied implants. Larger implants of course would offer the opportunity to increase the load of bioactive factors. However, the effect of higher drug doses on osseointegration has to be carefully tested, Based on previous reports in the literature (Peter et al., 2006, text reference), there seems to be an optimal dosage, especially for the use of bisphosphonates.

Reviewer II: The aim of this work was to assess the impact of surface modifications on implants osseointegration and anchorage in a severely osteoporotic rat model. The study suggests that most surface modifications that have a positive effect in healthy bone may not have it in osteoporotic bone anymore. It is surprising that an effect is seen in bone-implant contact and bone density around implants, but this doesn't translate into a mechanical benefit. Could the authors comment on this discrepancy? Authors: Although the constituents of bone are present (as evidenced by the mineral content and the bone-implantcontact), the development of these constituents into a fully-functional and integrated composite is delayed or compromised in osteoporotic bone. This may be seen as analogous to the difference between immature woven bone and fully remodelled, functional bone.

Reviewer II: What was the rationale to choose removal tests rather than pull-out or shear resistance tests? Have the authors considered FE modelling to numerically estimate pull-out strength from the microCT data?

Authors: Removal torque testing of threaded implants is a reliable method for determining the influence of surface treatments on osseointegration, which is less sensitive to testing artefact. Push-out, pull-out or shear tests are either subject to end effects with axial loading into the bone, require a substantially-sized implant to facilitate pull-out testing, or require specimen sectioning to perform shear tests. Any cutting of the implant/bone interface, e.g. to produce a standard push-out or shear test specimen, brings with it the risk of damaging the bone-implant interface. In the rat model, the chosen implant and torque test have the advantage of providing a low-profile implant head, which requires no further specimen preparation before performing the biomechanical test. The entire bone can be mounted for testing and the implant must not be strongly clamped in the testing machine to perform the measurement; it requires only a form-fit adapter and therefore no mechanical load is placed on the implant prior to testing.

FEA based on microCT has been shown to be inaccurate in the prediction of interfacial mechanical behaviour, as the true nature of the interface (bonded or non-bonded) cannot be determined a priori and non-bonded interfaces are computationally expensive. Therefore, FE models based on microCT rarely provide an accurate prediction of interfacial stiffness or strength. 
Reviewer III: If (especially a straight) implant is loaded with a specific coating, how can the authors be sure not to detach the coating while installing the implant screw, leading to a very high concentration in the upper part and only a very low concentration in the lower? The implant thread design looks very aggressive, would you expect the same results even with an implant with more shallow threads, leaving less space between the bone and the implant?

Authors: The selected implant thread design serves to enable primary implant stability in this reduced bone quality. In this animal model, more shallow threads may cause micromotion and thus impede a possible conclusion on surface coating effects. Due to the low concentration of agents, very thin layers below $5 \mu \mathrm{m}$ thickness were produced. The applied coating method produces relatively homogenous layers that strongly attach to metal surfaces. Certainly mechanical friction during implant insertion will influence the coating especially in the tip areas. However, due to the prior implant surface modification by sandblasting and acid etching, the coating components also penetrate into surface pores, thus being secured from friction during implant placement. The demonstrated effects of coating agents demonstrate sufficient remaining agent on the surface.

\section{Additional References}

Scholz-Ahrens KE, Delling G, Jungblut PW, Kallweit E, Barth CA (1996) Effect of ovariectomy on bone histology and plasma parameters of bone metabolism in nulliparous and multiparous sows. Z Ernahrungswiss 35: 13-21.

Scholz-Ahrens KE, Delling G, Stampa B, Helfenstein A, Hahne HJ, Acil Y, Timm W, Barkmann R, Hassenpflug J, Schrezenmeir J, Gluer CC (2007) Glucocorticosteroidinduced osteoporosis in adult primiparous Gottingen miniature pigs: effects on bone mineral and mineral metabolism. Am J Physiol Endocrinol Metab 293: E385395. 